\title{
Culture Matters: A Test of Rationality on Economic Growth
}

\author{
Joseph Ato Forson ${ }^{1}$, Jakkaphong Janrattanagul $1^{2} \&$ Emmanuel Carsamer ${ }^{3}$ \\ ${ }^{1}$ Graduate School of Public Administration, National Institute of Development Administration (NIDA), \\ Thailand \\ ${ }^{2}$ Wang Yanan Institute for Studies in Economics (WISE), Xiamen University, China \\ ${ }^{3}$ Graduate School of Development Economics, National Institute of Development Administration (NIDA), \\ Thailand
}

Correspondence: Joseph Ato Forson, Graduate School of Public Administration, National Institute of Development Administration (NIDA). 118 Moo3, Seree thai Road, Klong Chan, Bangkapi, Bangkok 10240, Thailand. Tel: 66-8-4072-4426. E-mail: datoeagle@yahoo.com

\author{
Received: February 26, 2013 Accepted: May 15, 2013 Online Published: June 29, 2013 \\ doi:10.5539/ass.v9n9p287 URL: http://dx.doi.org/10.5539/ass.v9n9p287
}

\begin{abstract}
There are widespread debates as to whether cultural values have a bearing on economic growth. Scholarly articles have actually had conflicting results with proponents arguing there is whiles opponents have thought otherwise. The aim of this paper is to verify the assertions made by these two schools of thought from the perspective of culture as a rationality component using an input-output growth model. We basically employed an approach that sought to define and aggregate cultural values under rationality indices: instrumental, affective, value and traditional rationality from 29 countries with data from world value survey (1981-2009). We systematically had them tested in an endogenous growth model alongside traditional economic variables. We conclude that when these cultural variables are combined with the so-called economic variables, there is an improvement in the model explanation than before. In addition, two of these cultural indices indicated a statistically positive effect on economic growth (instrumental and affective rationality). However, traditional rationality index was also robust but with a negative coefficient. Value rationality showed a somewhat weaker link to economic growth and was statistically insignificant. The policy implications of these findings are also discussed.
\end{abstract}

Keywords: economic growth, rationality, cultural traits

\section{Introduction}

Why do economies grow? Why should they grow? Why do we want them to grow faster? What are the necessary fundamental prerequisites for economies to grow? These are the sort of questions that economic performance and macroeconomic subjects are concerned with. Economists, Political scientists, Sociologists and Policy decision makers are concerned with economic performance. A number of growth theories have been developed to explain growth experiences of countries over time especially in the context of the dramatic economic performance of East Asian economies in recent times. This has exacerbated interest and stimulated a discourse on economic development with references made and lessons drawn from events such as the industrial revolution and the Second World War which continues to hold relevance due to the devastation most of the countries involved underwent. This actually brought a great deal of differences in the trend of economic development across nations. After half a century, most of the world economies are still stacked in the depression of underdevelopment. This has created some sort of artificial delineation: the western economies that represent the developed world, followed by developing economies or better still what has come to be known as "emerging economies" or the BRICS and lastly what has been termed as "Less Developed Countries" (LDC). These delineations have even been deepened by global fluctuations. With most of the world economies recovering from the shock and memories of the 2008 global economic downturn, the world still remains ascetically divided between affluent and underprivileged, democratic and authoritarian, just and unjust, orderly and chaotic. These differences are so conspicuously clear to even the casual spectator that we live in highly disjunctive times. This has generated a lot of explanations pinpointing to the underlying causal factors. Geography, climate, previous historic situations such as colonization among others have been 
mentioned as a possible cause of this huge economic divergence. However, cultural traits and its influence on economic growth seem to have been given less attention. The reason for this gap is easily traceable. Anything invoking cultural attributes, values and predisposition according to Patterson has been pushed and sidelined within the field of social sciences and policy circles (Orlando, 2006). One would therefore be wondering why such a marginalization? The obvious answer to this is simply due to the fact that culture is difficult to address on several levels. What is perceived as culture in one locality or region might not be applicable to another. This makes culture definitionally problematic. Its relativity and ambiguity affected by contextual factors is actually difficult to objectify and assess.

Recent causal factors on economic growth have been expounded from different angles and theories. These divergent views have established a somewhat two strands or schools of thought. The first and widely known group is the neoclassical group based on Solow's growth model which emphasizes the importance of investment. The second and most recent group- known as the theory of endogenous growth propounded by Romer and Lucas has also shed more light on the essence of human capital and innovation capacity (technology). Besides these two economic think tanks, there have also been other contributions from Myrdal's cumulative causation theory Myrdal $(1957 ; 1968)$ and another from the New Economic Geography School (NEG). Others such as McClelland et al., (1953; 1961), Weber (1958), Fukuyama (1995), Jackman (1996), Granato et al., (1996), Landes (2000), Shixue (1998), Jonathan (2009) have all highlighted on the significant role non- economic factors play on economic growth. The emergence of this area has given rise to yet another distinction between what Petrakos et al., (2007) termed as 'proximate' and 'fundamental or ultimate' sources of growth.

However, with the exception of few of these works, most publications on economic development have centered on the 'proximate' sources of growth. The proximate group advocate on issues such as accumulation of capital, labor and technology. On the 'ultimate' group, most research works (Weber, 1958; Shixue 1998) have been done theoretical without empirical backing. It is only in most recent times that others such as Granato et al., (1996) and Jonathan (2009) correlated cultural factors to economic growth with data collected from the world values survey database. For instance, in the work of GIL (1996), that was developed based on the shortcomings of McClelland et al., (1953;1961), collected data from 25 countries from the world value survey database. They systematically tried to test the robustness of "achievement motivation" index on economic growth. As part of their findings, they concluded that there exist significant relationship between achievement motivation index and economic development. However, their work received a lot of critiques from James Miller, Jackman and most recently by Jonathan Hanson (2009). These criticisms span from the sample size to the inability of their model to predict the future except the past. Jonathan Hanson (2009) in an attempt to address and object GIL's findings, has also tested the validly of earlier results and has concluded that there is no such relationship between achievement motivation and growth. He did this by increasing the sample size from 25 to 42 countries and also extended the years from 17 to 27 years. Other areas such as culture and climate, and culture as a predictor of organizational performance has also come to contribute to on-going debates (Alexander \& Kumaran, 1992; Coyne, 2009; Denison, 1996; Vaughan, 2003; Wilderom et al., 2000). Approaches such as Denison organizational culture survey (DOCS) contextualized in Hong Kong and elsewhere have been used in surveys extending beyond 15 years of research with data from over 1,000 low and high performing organizations with focus on four culture traits: mission, consistency, adaptability and involvement seen to have impact on organizational performance. Most results indicated a positive link of culture traits to organizational performance. Guido (2009) adopted indicators of individual values and beliefs, such as trust and respect for others, and confidence in individual self-determination as a measure to ascertain the link between these culture traits to economic development in the European context. Tabellini's findings were in line with earlier submission and we argue that, with the exception of the extensive data set used in the European context, his approach is not different from others such as GIL, Jonathan Hanson etc. Faria and Leon- Ledesma (2004) also argued that cultural values that emphasis hard work affects labor supply. In their views, work is like a habit forming. They indicated that in the case of habit forming, the labor supply is higher than neoclassical case and can further lead to higher level of consumption, capital stock and output. Cozzi (1998) also asserts that culture affects technological innovations. He however points out that culture in itself bears no utility and that its survival is linked to its positive effects on productivity. Cozzi generated technological innovations as an externality in his model by the aggregate investment in bubble culture. In a similar study, Johnson and Lenartowicz (1998) investigated the relationship between cultural factors and economic growth. They concentrated on values like uncertainty avoidance, conservatism and hierarchy (economic freedom and economic growth). They found a strong and robust relationship between economic freedom and economic growth and weak uncertainty avoidance and high level of individual autonomy. Yuriy 
and Roland (2010) in their preliminary research publication investigated the relationship between cultural variables and growth by constructing an endogenous growth model. They used individualism-collectivism as the main cultural traits and sought to predict how this trait has a bearing on growth. Their work was an improvement of Hofstede's 2001 work, which used surveys among IBM workers in 30 countries. Yuriy and Roland expanded this number to 80 countries. Their results were quite similar to Hofstede's work. They found a strong and robust relationship of culture traits on long-run economic growth. They conclude that individualism should lead more to innovation due to the social rewards and that this cultural effect may offset negatives of bad institutions on growth. From the above developments, it is evident that the "ultimate or fundamental' source of growth has had limited attention and that findings on the relationship between cultural factors and economic development has not been straightforward. We are therefore left to wonder if there actually exist any sort of relationship between cultural factors and economic growth. If yes, can it be measured and its effects compared with traditional economic factors such as savings and investment? Can cultural factors increase the coefficient of determination in a typical growth model to nib in the bud the problem of "Solow residue"? These questions and others constitute the basis of this research. Our desire to do this research work is informed by the questions raised above and the limitedness in research publications in this area. We are also aware of the fact that most empirical research have centered on achievement motivation index. In this study, we make use of cultural variables that encompass achievement motivation index and extend it based on Weber's (1958) definition of culture, hence allowing us to derive four rationality indices.

The focus of this paper however, is to contribute to the on-going debate using growth theory to explain this divergent level of development with cultural factors being the centerpiece. Earlier empirical study on growth using the typical Solow-type neoclassical theory have been criticized on the ground that physical capital and the model at large fails to accounts for cross countries income disparities with a high "Solow residue". Cultural factors have been identified as part of those Solow residues. Mainstream researches on cultural factors have been limited to theoretical and exploratory design type where factors are explained without quantifiable empirical backing. For instance works such as the ones by Shixue (1998) and others have resorted to theoretical means of finding explanatory factors to buttress culture and its relationship to economic development. To make this paper distinctive enough, we employ an approach in which a wide array of data set from 948 societies are considered for sampling from the world value survey database from 1981 to 2009 . Our task has been to sample out 29 countries across the seven continents with their distinctive cultural values. These cultural values sampled are regrouped into four main rationality indices- instrumental rationality, affective rationality, value rationality and traditional rationality. Our understanding of the term rationality is based on human attempt to objectively recognize the optimal path between means and end. This approach to human rationality reflects the influence of economics, as humans are perceived to be rational utility maximizes, implying inherently, self interested and behaviorally responsive in such a way as to seek out optimal strategy given the structural context to satisfy their goals (Checkel, 1998; Rittberger, 2002).

\section{Conceptualization and Key Variable Measurements}

\subsection{Definition of Culture}

To understand how culture can affect economic growth, it is important to understand what culture is and how it has been perceived, understood and defined by different researchers in different context. However, culture just as we pointed out in our introduction is difficult to define. Our description and definition of culture can be captured in three perspectives: the content, as a way of life of a group of people and the formation of culture. Its subjectiveness makes it a bit difficult to objectify. Nevertheless, in the light of these difficulties, certain writers have been able to define it to suit their various works or purposes. This has brought some sort of intellectual rift between historical economists and these scholars (culture writers) who are fans of culture.

Culture has been defined in many ways in the literature. For example, Schein (1985) defines culture as "a pattern of basic assumptions that the group learned as it solved its problems of external adaptation and internal integration, that has worked well enough to be considered valid and that, therefore, is taught to new members as the correct way to perceive, think, and feel in relation to those problems". Hofstede (1984, p. 21) defines culture as "the collective programming of the mind which distinguishes the members of one human group from another." The GLOBE research program (House et al., 2004, p. 15) defines culture as "shared motives, values, beliefs, identities, and interpretations or meanings of significant events that result from common experiences of members of collectives that are transmitted across generations." Several frameworks for measuring national culture dimensions can be found in the academic literature (Hofstede, 1984; Trompenaars and Hampden-Turner, 1997; Schwartz, 1994; House et al., 2004). Over the last three decades, Hofstede's research represented the most common framework to assess the dimensions of national culture (McSweeney, 2002). The 
Hofstede survey of 80,000 IBM employees in 66 countries established four dimensions of national culture: power distance, uncertainty avoidance, individualism vs. collectivism, and masculinity vs. femininity. However, McSweeney (2002) argues that measurement reliability and validity are the principal weaknesses of Hofstede's dimensions. For example, Hofstede didn't present Cronbach alphas for the items that make up the indices. In addition, a close examination of the number of questionnaires used by Hofstede reveals that the average number per country was small (McSweeney, 2002). Schwartz (1994) argues that the two major weaknesses of Hofstede's research are his sample plan and historical change. First, Hofstede obtained data from employees of only a single multinational corporation (IBM). Second, Hofstede's analyses were based on data gathered from 1967 to 1973. During the three decades since his last data collection, major cultural changes have occurred throughout the world. GLOBE (House et al., 2004) addresses these shortcomings and provides the most updated cross-cultural study based on data gathered in the recent decade. The GLOBE project involves 150 social scientists and management scholars from 61 countries representing all the major regions of the world. They identified nine cultural dimensions. The development of the GLOBE scales involved extensive testing for reliability and validity (House et al., 2004).These subjectiveness in culture definition prompted people like A.L. Kroeber and Clyde Kluchohn (1952) to list about 160 definitions in their work over a period of 80 years of research. We can identify over 160 definitions of the term with reference to the field of social sciences (psychology, anthropology, sociology and others).

Earlier usage of the word "culture" has always been linked to farming hence "agri-culture". It was during and after the $16^{\text {th }}$ century that there were some modifications. There has since been an extension to broaden the scope by the inclusion of human characteristics such as mind, manners, spirit, sensibility and taste. The $18^{\text {th }}$ century elite Europeans used the term culture to draw the dichotomy between the honored western Europeans and what those that could not develop these human qualities outside Europe and those who were poor. The term however received its first usage to signify a noun when it was used by a German Historian Herder implying that all peoples "had" a culture. The term has since seen changes from time to time. Others such as A.L Kroeber (1952) have related culture to be subservient to beliefs, customs, and knowledge, art of technologies, rules and ideal as consisting ideals and rules and what we are being taught either from man or through personal experiences. In 1952, Clyde and Kluchohn (1952) added new dimension to the notion of culture by arguing culture basically incorporate patterns that are both explicit and implicitly generated and transmitted symbols based on the achievements of human groups embodied in artifacts. They continue in their argument that culture is simply a product of action historically derived. Lawrence Harrison $(1985 ; 1997)$ also tried to define culture in a simple manner. He stated that culture refers to attitude and values that guide human action in a society. Others like Nobel laureate and economic historian Douglass North views and defines culture in the realm of institutions and institutional change. He views culture as the knowledge acquired or transmitted from a generation to another through teaching and learning by imitation (North, 1990).

We can infer from the above definitions and descriptions that culture as a subject matter is not that straightforward to tackle. However, it is also evident that there are a lot of commonalities in the definitions and opinions shared by some of these writers. The sort of core elements mentioned were quite similar and kept appearing in each other's work. In this research work, we define culture simply as the implicit force that is inbuilt that prompts individuals to behave in a certain rational manner (action). These implicit forces are the set of values or norms imbued in the individual by learning. Defined this way, we can appreciate that culture does not only affect social norm but also economic activities like the propensity to consume and save, fertility choices, investment in education among other economic variables. These implicit force(s) are open to changes from time to time. We view this definition to be synonymous to the ones given by Max Weber, A.L Kroeber and Clyde Kluchohn and Lawrence Harrison. Invariably, the complex and vast nature of culture as a concept involves a lot of elements which makes it too general to be captured by a single trait, idea or object. Thus when one intends to examine the role of culture on economic growth, one has to look for a proxy for culture. Previous studies to infer economic growth from culture have relied on historical evidence without any quantitative backing. The end results of these studies have been criticized on the basis of its subjectivity and relativity. We seek to use a cultural proxy that can be tested and validated to give a particular empirical outcome and which can be replicated by others in different settings, location and context.

\subsection{Aggregation of Cultural Indices}

In aggregating the various cultural traits to form an index or indices as described and defined by the various writers above, we sought to rely on the definition by Max Weber (1958), who played a pioneering role in investigating the relationship between culture and development. See further these well-known books- The Protestant Ethic and the spirit of Capitalism (1958) and The Religion of China: Confucianism and Taoism. 
Weber defined culture on the basis of rationality or action. Weber defines "action" as behavior invested with an individual's subjective meaning and culture is "a segment on which human beings confer meaning and significance"-we can conclude that culture, in its very nature, is reflected in people's action. All individual action may be oriented in four ways: instrumentally rational, value-rational, affective (especially emotional) and traditional rationality. We worked to identify the various traits as it is related to the level of action or rationality mentioned from the survey response.

Traditional rationality (TR) or behavior is determined by long standing habits: actions based on tradition. For instance relaxing on Tuesday in some part of West Africa is viewed as a traditional custom. The violation of such rules is punishable in diverse circumstances. Traditional Rationality is expressed as customs or norms meant to govern societies and are observational and learned from generations to generations. Humans detect social cheating with much greater reliability than isomorphic violations of abstract logical rules. Here, we try to identify in our survey responses traits that fall under TR. Collecting a set of these traits would help us to come out with TR index.

Affective Rationality (AR) is strongly associated with strong feelings (emotional) for something. Emotions are an integral part of being human; we all express them and they shape the character and contents of our lived experiences. Emotion is functionally integrated alongside cognition in how we reason. Specific traits that relates to AR that relates to this description are collected from the survey responses. Those actions are emotional laden.

Value rationality (VR) is determined by a conscious belief in the intrinsic value of acting in a certain way. Value-rational action, wert rational is an action that one will opt for due to the fact that it leads to the ultimate goal without preconception of the consequences and the appropriateness of the path/means to be used to achieve such a goal. Specific traits that relates to VR may include but not limited to hard work, confidence, frugality, generosity/corruption, grandeur and determination.

Instrumental rationality (IR) is determined by a consciously calculating attempt to achieve desired ends with appropriate means. This is a direct opposite to VR though the detail of it might be treated as value rational. It is pursued after evaluating its consequences and consideration of the various means to achieve it. They are usually planned and taken after considering costs and consequences. Specific traits that fall under IR are but not limited to hard work, tactfulness, confidence, speech, thrift, discipline, commitment, worldly achievement, governments intents to construct irrigation projects etc.

\section{Research Methodology and Model Specification}

To account for the contribution of factor accumulation and measure the impact of the different factors in the economic growth, this paper employs the input-output data model. Capital from other forms of physical capital and human capital inputs and some cultural traits that produce output in the form of real GDP.

For this purpose, the model taken is the original Robert Solow (1956) model of exogenous growth with technological progress. The centerpiece of the standard neoclassical growth model developed by Solow is an aggregate production function of the form:

$$
\mathrm{Y}_{\mathrm{t}}=\mathrm{K}_{\mathrm{t}}^{\alpha}\left[\mathrm{A}_{\mathrm{t}} \mathrm{L}_{\mathrm{t}}\right]^{1-\alpha} \quad 0<\alpha, \beta
$$

Where $Y$ is output, $K$ is capital, $L$ is labor and A an index of technology or efficiency, constant returns to scale, decreasing returns to each input and a positive and constant elasticity of substitution. The fundamental dynamic equation of the model relates to the evolution of the capital stock to a constant rate of savings and a constant rate of depreciation. Labor and the level of technology grow at exogenous exponential rates.

\subsection{Mankiw, Romer and Weil Model}

Mankiw, Romer and Weil (1992) present a simple extension to the Solow model by letting human capital enter as a separate input into an otherwise standard Cobb- Douglas production function with technological progress. The production technology in this model thus assumes the following form:

$$
\mathrm{Y}_{\mathrm{t}}=\mathrm{K}_{\mathrm{t}}^{\alpha} \mathrm{H}_{\mathrm{t}}^{\beta}\left(\mathrm{A}_{\mathrm{t}} \mathrm{L}_{\mathrm{t}}\right)^{1-\alpha-\beta} \quad 0<\alpha, \beta \alpha+\beta<1
$$

Where $Y$ is output, $K$ is capital, $H$ is the stock of human capital, $A$ is the level of technology and $\mathrm{L}$ is "raw" labor. The exponents $(\alpha, \beta$ and $1-\alpha-\beta)$ measure the elasticity of output to the respective inputs.

Like in the Solow model, the population and the level of technology grow at the exogenous rate $n$ and $g$ respectively while capital depreciates at the rate of $\delta$. Following Solow, Mankiw et al., (1992) rewrite income, physical and human capital in terms of quantities per unit of effective labor etc. the changes over time in physical and human capital per unit effective labor are: 


$$
\begin{aligned}
h_{t}^{\prime} & =s_{h} y_{t}-(n+g+\delta) h_{t} \\
k_{t}^{\prime} & =s_{k} y_{t}-(n+g+\delta) k_{t}
\end{aligned}
$$

Where $\delta$ is proportionate depreciation for both physical and human capital, savings rates for physical and human capital respectively which are assumed to be constant over time, though not across countries. Solving for the steady- state solutions $\mathrm{k}^{*}$ and $\mathrm{h}^{*}$, Mankiw et al derived an equation for steady- state income growth in this form;

$$
\ln \left[\left(\frac{Y_{(t)}}{L_{(t)}}\right)\right]=\ln A(0)+g t+\frac{\alpha}{1-\alpha} \ln \left(s_{k}\right)-\frac{\alpha}{1-\alpha} \ln (n+g+\delta)+\frac{\beta}{1-\alpha} \ln \left(s_{h}\right)
$$

The physical capital savings, $S_{k}$ was approximated by the investment share in GDP. Human capital savings rate $S_{h}$ was measured by the proportion of the working age population at any one time enrolled in secondary school. Mankiw et al estimated equations on cross-section samples of 98 and 75 countries respectively in 1985 yielded great improvement compared to Solow, while the implied income shares of physical and human capital, both around 0.3 were judged to be plausible.

Lucas (1988) also had earlier on shared the same notion on this by arguing that the development of human capital in terms of both education and "learning by doing" also play important role on economic growth. We can therefore also argue that series of factors can be developed that are influenced by cultural beliefs, values and social norms which have important consequence on economic growth and include them in the typical neoclassical growth models whose empirical estimation can show their probable effects on economic growth.

Given the thrust of this paper positioned on cultural traits and its effects on economic growth, we would include these cultural factors and have it augmented with the traditional economic factors in our growth model and thus the empirical endogenous growth models used in this study assumes the following form:

$$
\mathrm{Y}_{\mathrm{t}}=\alpha+\beta \mathrm{I}_{\mathrm{i}, 0}+\prod \mathrm{X}_{\mathrm{it}}+\varepsilon_{\mathrm{i}}
$$

Where $Y_{i}$ is output growth (per capita) for country i, $I_{i, 0}$ is a set of economic variables estimated at the beginning of the time period for country i. The indicator for human capital is the gross number of student enrolled at primary and secondary education institution vis-à-vis the total population of that age group. It was difficult getting complete data on the indicator for physical capital which is the value of gross fixed capital formation (including acquisition less disposals of valuable) so it was omitted in the regression analysis and indicator for investment is the ratio of real domestic investment to GDP (i.e. expenditure on education as a share of GDP). Indicator for initial level of wealth is GDP per capita (income) and the rate of growth of GDP in real terms. Empirical evidence on these variables has shown that they are able to predict economic performance across nations (See Levine 1992; Sala-i-Martins 1997; Barro R. 1990; 1991). X is a set of cultural variables for the various levels of rationality (i.e. IR, TR, VR and AF) for time period of i country. $\varepsilon_{i}$ is the noise component/error term for country i.

\subsection{Data Description and Hypothesis Formulation}

The data set for this study is obtained from world value survey to compute for the various cultural traits as defined and aggregated into indices as mentioned earlier on. Out task here is to identify these traits as many as possible and assign weights to them. The world value surveys (Survey, 2010) capture individual beliefs and values which reflects social norms and customs. To improve the sample size, survey data of the chosen 29 countries (Australia, Bangladesh, Botswana, Brazil, Canada, Chile, China, Colombia, Czech Republic, Denmark, Ghana, Hong Kong, Hungary, India, Indonesia, Japan, South Korea, Malaysia, Mexico, New Zealand, Peru, Russia, Singapore, South Africa, Switzerland, Thailand, Turkey and the United States) is pooled in waves for the time period of 1981-2000 and 2000-2009 representing 29 years. We make use of the survey to derive and aggregate the data to create culture variables for each period. The data on economic variables used in the model are obtained from the World Bank data centre (Data, 2009) and Levine (1992) work. We specifically made use of the averages of these economic variables from the countries involved to conform to the data arrangements of the cultural variables in a time series orientation. Cultural traits were inferred from the questions posed in the survey response as provided by the World Value database. Weights were assigned to each trait by virtue of how it was responded in the survey for the countries involved.

The variables for the model are as follows: $Y_{t}=$ Growth Rate of GDP per capita; $H_{t}=$ Human capital measured by the number of gross school enrollment at both primary and secondary levels, GDP per capita income and $\mathrm{I}_{\mathrm{t}}=$ Investment measured by expenditure on education as a share of GDP percent. 
Dependent Variable: Output is defined as Log Growth Rate of Gross Domestic Product. The data for GDP is obtained from World Bank data source, OECD on the countries sampled and the work of Levine (1992).

Independent variable: Log GDP per capita income, human capital $(\mathrm{H})$ measured by both primary and secondary enrollments, Investment (I) measured by Government spending on education as a share of GDP and our cultural indices for IR, VR, TR and AF. Having described and defined the variables involved, and based on the fact that this research is on culture and its effects on growth, we formulate the following hypotheses to serve as a guide in our task;

$H_{0}$ : Culture is positively associated with economic growth with high level of $I R / A F$ and low levels of $T R / V R$

$H_{1}$ : Culture is negatively associated with economic growth with low level of $I R / A F$ and high levels of $T R / V R$

\section{Estimated Results and Interpretation}

We begin our analyses with a diagnostic check on the data set to make sure we do not violate any of the assumptions of parametric statistics. Table 1 below is the descriptive statistics and correlation matrix of the independent variables used in this study.

Table 1. Descriptive statistics and correlation matrix

\begin{tabular}{|c|c|c|c|c|c|c|c|c|}
\hline Variable & 1 & 2 & 3 & 4 & 5 & 6 & 7 & 8 \\
\hline IR (1) & 1 & & & & & & & \\
\hline $\operatorname{VR}(2)$ & $.229^{*}$ & 1 & & & & & & \\
\hline $\mathrm{AF}(3)$ & .085 & .135 & 1 & & & & & \\
\hline $\mathrm{TR}(4)$ & $-.255^{* *}$ & $-.59^{*}$ & -.224 & 1 & & & & \\
\hline LOG_GDP(5) & $.07 * *$ & $.027 * *$ & .055 & $-.087 * *$ & 1 & & & \\
\hline PRIM_ENROL(6) & .206 & -.009 & $.09 * *$ & -.005 & $.536^{*}$ & 1 & & \\
\hline SEC._ENROL(7) & $.406 * *$ & .148 & $.118 * *$ & .033 & $.537 * *$ & $.482 * *$ & 1 & \\
\hline INVES_GDP(8) & .217 & -.11 & -.043 & .015 & .002 & .166 & -.065 & 1 \\
\hline Mean & .070 & .089 & .162 & 3.956 & 3.405 & 1.010 & .452 & .218 \\
\hline Std. Dev. & .373 & .377 & .330 & .193 & 2.008 & .156 & .235 & .043 \\
\hline Min & -.460 & -.460 & -.460 & 3.640 & .533 & .750 & .030 & .139 \\
\hline Max & .900 & .900 & .900 & 4.280 & 7.380 & 1.330 & .860 & .317 \\
\hline Skewness & .455 & .510 & -.046 & -.253 & .090 & .097 & -.143 & .295 \\
\hline Kurtosis & -.402 & -.333 & .372 & -.774 & -.980 & -.093 & -1.163 & .444 \\
\hline
\end{tabular}

Notes: ${ }^{* *} \mathrm{p}<0.05,{ }^{*} \mathrm{p}<0.01$ sig. (1 tailed).

Table 1 is the descriptive statistics and correlation matrix results of the independent variables. In statistical literature, when correlation between variables exceeds 0.75 , such variables are highly correlated and thus violate the assumption on multicollinearity. However in our case, all variables are lower and some are even negative. We can proceed to work with all of them.

The correlation matrix and descriptive statistics in Table 1 is quite straightforward and interesting. A quick glance at the descriptive shows the data set is fairly normally distributed with skewness and kurtosis being within the accepted range. We can also infer from the correlation matrix that there is a lot of soundness in the aggregation of the responses and the economic variables from the survey data. Most of the indices indicate positive and lower correlation and are significant at 5 percent ( 1 tailed). With all of our independent variables below the 0.75 acceptable criterions, we can proceed to estimate the regression coefficients for the periods 1981 to 2009 in three different models.

We extend our analyses further by estimating relevant standard multiple regression functions using OLS in a baseline endogenous growth model that includes variables already proven to have shown robust partial correlation with economic growth. In this regard, we would tread on the same path with (Levine, 1992; 
Granato et al., 1996; Roland, 2010). Using time series data from our 29 countries, we then test in accordance with equation three above.

Table 2. OLS estimation of economic growth (Dependent variable: LOG growth rate of GDP)

\begin{tabular}{|c|c|c|c|c|c|c|c|c|c|}
\hline Variables & Model 1 & & & Model 2 & & & Model 3 & & \\
\hline & Coefficients $(\beta)$ & $\mathrm{T}$ & Sig. & Coefficients $(\beta)$ & $\mathrm{T}$ & Sig. & Coefficients $(\beta)$ & $\mathrm{T}$ & Sig. \\
\hline Constant & -0.315 & -0.166 & 0.109 & 1.508 & 1.977 & 0.060 & $1.525^{* *}$ & 2.523 & 0.020 \\
\hline LOG_GDP & $-0.509^{* *}$ & -2.598 & 0.016 & & & & $-0.590 * *$ & -3.585 & 0.002 \\
\hline PRIM_ENROL & 0.379 & 1.949 & 0.063 & & & & $0.412 * *$ & 2.766 & 0.012 \\
\hline SEC_ENROL & $0.353^{* *}$ & 1.875 & 0.007 & & & & $0.415^{* *}$ & 2.369 & 0.028 \\
\hline INVEST_GDP & $0.462 * *$ & 2.887 & 0.023 & & & & $0.429 * *$ & 3.279 & 0.004 \\
\hline $\mathrm{AF}$ & & & & $-0.352 * *$ & -2.155 & 0.041 & $-0.414 * *$ & -3.405 & 0.030 \\
\hline IR & & & & $0.474 * *$ & 2.867 & 0.009 & $0.105^{* *}$ & 2.29 & 0.048 \\
\hline $\mathrm{TR}$ & & & & -0.284 & -1.401 & 0.174 & $-0.486^{* *}$ & -3.010 & 0.007 \\
\hline VR & & & & -0.081 & -0.409 & 0.686 & -0.114 & -0.755 & 0.459 \\
\hline $\mathrm{N}$ & 29 & & & 29 & & & 29 & & \\
\hline $\mathrm{R}^{2}$ & 0.435 & & & 0.394 & & & 0.728 & & \\
\hline adjusted $\mathrm{R}^{2}$ & 0.341 & & & 0.292 & & & 0.619 & & \\
\hline $\mathrm{F}$ & 4.615 & & & 3.893 & & & 6.698 & & \\
\hline Sig. & 0.000 & & & 0.000 & & & 0.000 & & \\
\hline
\end{tabular}

Notes: $* * \mathrm{p}<0.05,{ }^{*} \mathrm{p}<0.01$.

Table 2 is the OLS estimation of economic growth. The estimation is done in three separate models with dependent variable of log Growth rate of GDP. Mean of dependent variable: 2.96 for all models. Beta ( $\beta$ ) reported here is the standardized beta.

Model 1 regresses a nation's growth rate of per capita GDP on its initial level of per capita income, human capital (primary and secondary enrollment), and investment (Spending on education). We found a negative coefficient (-0.509) on the initial level of per capita income. This buttresses the evidence of "conditional convergence". This we can interpret to mean, when both human and physical capital investment are controlled, poorer countries grow faster than richer ones. In other words, the rate of growth declines in a country's wealth (Income). Secondary enrollment used as one of the proxies for human capital bears a positive ( 0.353 percentage points) and is statistically significant on per capita growth. The result with investment was also significant with statistical effect on economic growth. For example, an increase in the level of secondary enrollment by a given percent will induce an annual growth rate of 0.353 percentage points higher on average on per capita growth. In the same way, the rate of investment has a positive effect on the growth rate. That is, with a given percentage increase in investment in education as a share of GDP, GDP Growth rate is expected to increase by 0.462 percentage points. The results here tend to support both the Solow-type neoclassical theory on income convergence and the endogenous growth theory on the spillover effects (externalities) of human capital development (Cypher, 2004). The model on the whole performs averagely well and accounts for about 43.5 percent of the variation in cross-national growth rates. This buttresses the point of Solow residue as there are other factors besides these economic variables that ought to be incorporated in this model. There is therefore the need to include other variables to boost the explanatory power of this model.

In Model 2, we regress the growth rate of per capita GDP on only a constant and our cultural indices. In this model, two of our cultural indices are statistically significant. AF and IR bear negative and positive coefficients of -0.352 and 0.474 and are statistically significant. This is in line with our prior expectation. The other two variables; TR and VR are both statistically insignificant and have negative/ weaker effects on 
economic growth. This we can interpret as, any change in these cultural traits by a given percentage will induce 0.352 and 0.474 of percentage points on economic growth. The model accounts for 39.4 percent in terms of cross national per capita explanation. Its fitness is fairly good but less than (Granato et al.,1996; Muhammad et al., 2010) models.
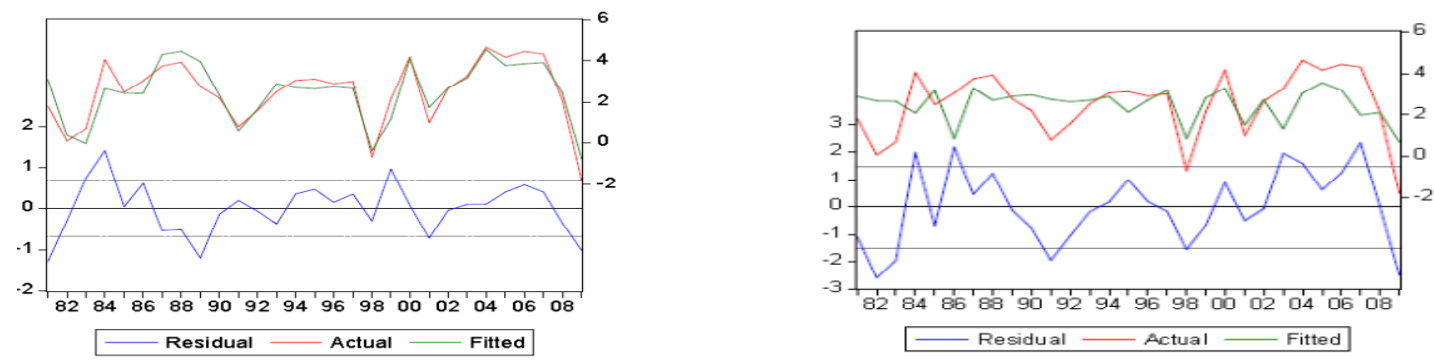

Figure 1. Residual of fitness graphs model 1 and 2

Note: Figure 1 shows the residual of fitness for model 1 and 2. The two Models have a relatively good fitness as it seemingly falls within range.

Model 3 combines both the economic variables with our cultural variables. The coefficient on AF has become lesser (-0.352) than its standard error implying it cannot be distinguished from zero with high confidence. IR continues to be significant, but with a lower coefficient when compared to model 2 above. Surprisingly, TR was statistically significant, but with a negative influence. Likewise, the coefficient on VR was also negative and statistically insignificant at -0.114 percent respectively. All the economic variables adopted are statistically significant when merged with the cultural variables in a model. There is an improvement in the explanatory powers of this model (about 72.8 percent) over previous models when the variables are increased. This partly resolves the problem of "Solow residue" as was the criticism brought against proponents of the neoclassical theory (Cypher, 2004: pp.243). We move a step further to test for normality of our data using Jarque- Bera test and heteroskedasticity (White test). We are investigating which of the hypothesis formulated should be accepted or rejected.
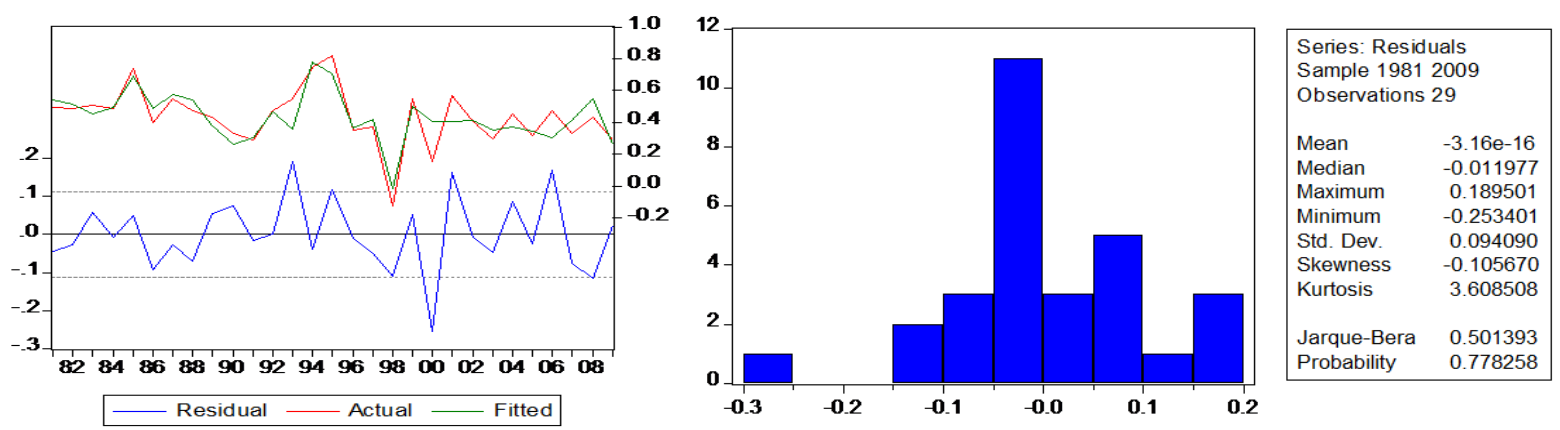

Figure 2. Residual of fitness graph model 3 and test of normality for model 3

From figure 2 and 3, a test of normality using Jarque-Bera, histogram and P-P plot shows that the residual is fairly normally distributed with $\mathrm{p}=0.778$ and Jarque Bera $=0.501$. In model 3 , we also test for heteroskedasticity (i.e. to ascertain whether the disturbances do not have the same variance) of which we found that $p=0.08$ is bigger than 5 percent so we by this accept the null hypothesis. The null hypothesis has no serial correlation. In general, model 3 accounts for 72.8 percent of the variation in cross-national growth rates. Its fitness and explanatory prowess is creditable and is seen as an improvement to both model 1 and 2. 

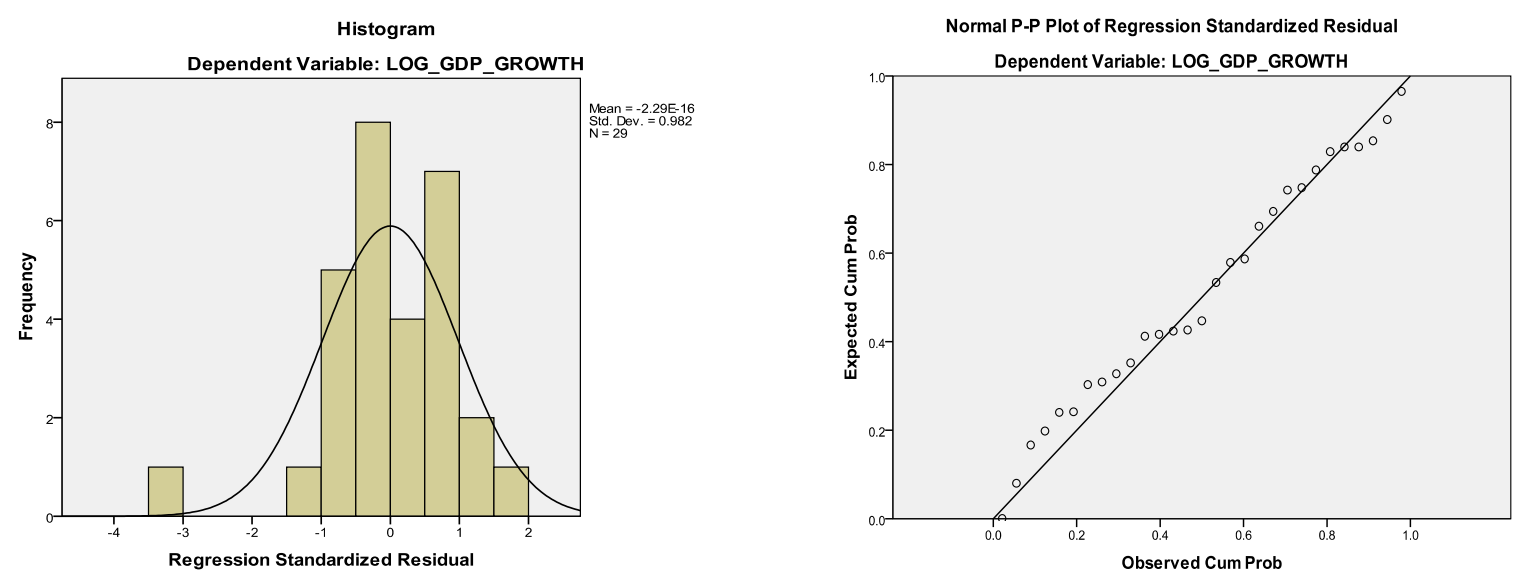

Figure 3. Normality test for model 3

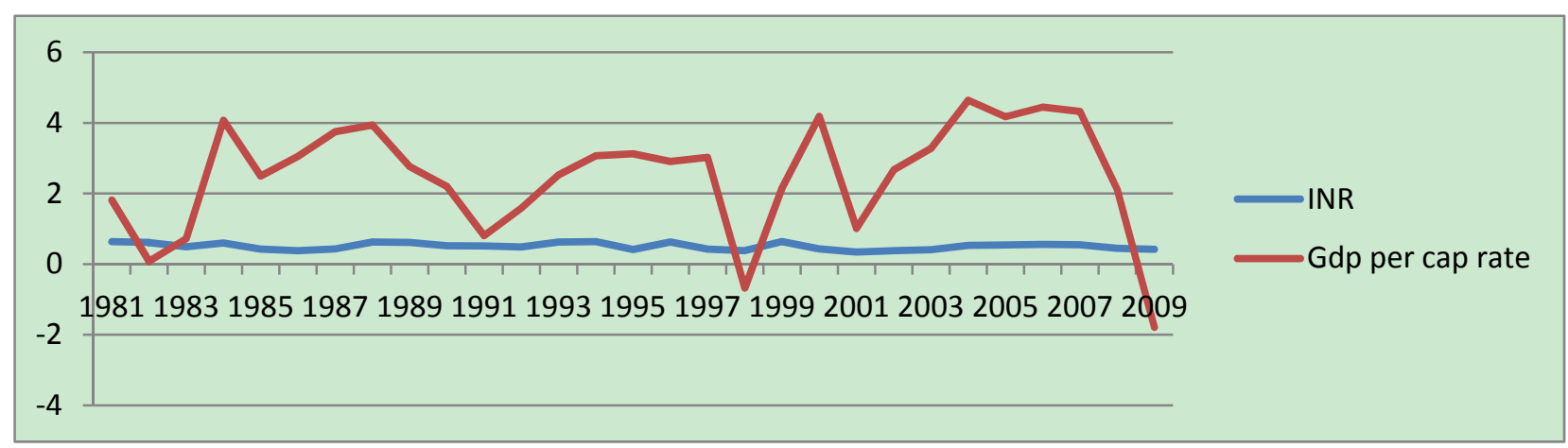

Figure 4. Relationship between GDP per capita rate and INR

Note: Figure 4 shows the relationship between the most influencing rationality index with GDP per capita ratio. It can be seen that instrumental rationality index is much more stable than GDP per capita ratio.

In figure 4, we attempt looking at the relationship between Growth rate of GDP per capita and the most influencing cultural variable (instrumental rationality). We comment that the trend is fairly stable with regards to the IR graph. In as much as there are conspicuous swings in the Growth rate of GDP per capita, IR has been relatively stable. However, the rate of GDP per capita has always been above the cultural variable. This affirms our earlier findings as IR being robustly significant to economic growth.

\subsection{Policy Implication of Results}

The essence of culture as a core influencing factor to economic growth is glaring and need not be repeated. However, the emergence of so-called modern theory in the classical world of economics has reluctantly overlooked this core influencing factor and has focused on the end results. By end results, we are implying savings, human capital formation, physical capital, technological advancement among others. The desire to pursue any of these end results is implicitly shaped by cultural traits or values. This notwithstanding, in as much as cultural traits are the core influencing factors leading to growth, we must be quick to emphasize that some traits are in themselves against or does not orchestrate economic growth.

To buttress these assertions, we considered certain traits and how they have shaped or influenced these so-called economic variables. Lewis (1955) points out that "self-control" which we identify as a trait affects savings behavior. Robert Malthus (1798) also admitted this notion of "self-control" in his theory of population growth and its aftermath effect on fertility choice that eventually influence investment in physical capital. Max Weber (1958) shared the same opinion in his well-known book. He proposed that some attitudes and values connected to protestant ethic like austerity, honesty, work, rationality and hard work has become the prerequisite of material progression and achievements. Concerning capital formation he wrote; 
"When the limitation of consumption is combined with this release of acquisitive activity, the inevitable practical result is obvious: accumulation of capital through ascetic compulsion to save". The restraints which were imposed upon the consumption of wealth naturally served to increase it by making possible the productive investment of capital (Weber 1958...p.32)."

Another cultural trait pointed out by Azariadis and Drazen (1990); the desire for "self-improvement" is seen to be the driving force behind the decision to invest in education allowing people to acquire skills and thus build human capital. Confucianism as a cultural value according to Herman Khan (1979) and other western scholars is seen to induce economic development. They draw attention to the fact that Confucianism inculcates diligence, abstinence, frugality and severity. Confucianism gives recognition to familial devotion, entrepreneurial spirit, hard work and patriarchal leadership. Leaders with selfless and patriotic behavior which typifies affective rationality put the welfare of their subjects at the fore-front thereby subduing their ego. This has been the success story of most Asian Economies in recent times. The impressive growth of the then Asian tigers was as a result of the inherent love of their leaders and the willingness of their subjects to work hard to ensure they developed.

Conversely, Gunnar Myrdal (1968) in one of his research works emphasized on how certain culture values or practices impedes economic development. He expressed that cultural factors are the principal obstacle to modernization. He argues that not only do they interfere with entrepreneurial activity, but they flood, rigidify and dictate the entire national system in its entire political, economic and social dimension. His main point of emphasis was against certain group of religion in certain parts of the world who consider pigs impure and have a strong dislike to having it included in their diet. This certainly interferes with the welfare and efficiency of most peasant farmers who perceive pig rearing as an alternative or even supplements to crop cultivation. He also argues that the ban on cow slaughter in India and Thailand bears very higher costs that are never calculated. On the issue of Confucianism, Max Weber (1958) and some anti-traditionalists have both expressed different opinions. For instance the latter argue that Confucianism is not beneficial since it conflicts with modernization in many directions. Max Weber's examination of Confucianism led him to conclude that cultural traits expressed in oriental religions explained why Asian development was much slower than Europe in those days. He stressed that the fundamentals of Confucianism was not well laden with similar kind of physic anxiety, as was in the European context of the protestant ethic.

In some parts of Africa especially Ghana, certain days of the week are recognized as the days of the gods. Both peasant farmers and fishermen are therefore prohibited from working on their farms or go on fishing on the designated day(s). This has a higher opportunity cost that could have concomitant effect on the general production output of the countries involved. This tradition undoubtedly is not development friendly. However, though the USA has been labeled as being traditionally rational, that hasn't affected its progress and eventually being the most successful country in history. Thus, not all traditionally rational societies are backward.

\section{Conclusion and Recommendation}

From our analysis, there is no denying the fact that economic growth is implicitly somehow shaped by cultural factors. This idea has received a lot of criticisms on the field of academia especially in the social sciences. As mentioned before, the reason for this is inherent in the notion that cultural values have been perceived to be widespread and therefore exist in almost all societies. Some school of thought are of the view that, if really culture value determines economic growth, then all efforts at achieving a greater height in economic development would proof a tall mountain to climb because culture cannot be changed.

In our studies, we could not cover almost all the cultural values or traits as captured by perhaps the survey in the various societies, but we believe randomly selecting a section of these values or traits and assigning quantities or weights to them for easy measure in an empirical manner scraps away the notion as expressed by some critics. This erases all sorts of stereotype ideas like African culture is not development friendly hence their underdeveloped. We can however focus on a particular trait(s) at a particular time and place and have them tested.

As can be inferred from our findings, we have come to appreciate that when culture is perceived under rationality and therefore grouped in accordance with our method, then anything that shares boundaries with tradition and value or norm may be detrimental in some sense to economic growth. However, notwithstanding this, the two other rationality indices scored creditably positive coefficients and were statistically significant affirming our prior expectation. Our findings are in line with (Weber, 1958; Shixue, 1998); whose research works were done to strike the dichotomy in the development levels between Asian economies and the Latin American and other parts of the globe. For instance Jiang Shixue's assertion of Asian norms or value being 
the main driving force for its recent remarkable growth as opposed to its Latin American economies was interesting, but we would have expected him to have highlighted on those traits in specific terms in such a manner that could have allowed him to model and then empirically have them tested. His findings would have been more concrete other than just an expression of notional ideas. The empirical backings as shown in this paper verify the idea or notional view as expressed by these writers. Though (Granato et al., 1996; Muhammad et al., 2010; Roland, 2010) also investigated how traits affect economic growth under a different approach, it is interesting to note that our work has vindicated them.

Regardless of our findings in this paper, it would be incongruous on our part to conclude that cultural traits have answers to all the explanatory factors leading to economic growth. There are other factors identified as possible factors that can help in explaining cross-national economic performance such as institutions (Governance), geographical factors, natural resources, business organization, Research and Development, growing internal trade etc. In that regard, we view the findings in this paper as prelude as it captures an aspect of these avalanches of factors. We also recommend an attempt to migrate from a time series analysis to a panel data analysis to provide a more rigorous result as there seem to be limited study that employs this approach. This is a serious area of concern and it's open for further research in the near future. We do hope that in the wake of the availability of data on both economic and cultural variables, we would in our subsequent research work go beyond this level and make use of panel data and also have any of the factors mentioned included. This we believe would give more meaning to our results. In addition, we would be working assiduously in improving our model and the control variables would be increased to improve the general performance of the model in terms of cross country explanation.

\section{References}

Alexander, K., \& Kumaran, P. (1992). Culture and development: culture patterns in areas of uneven Development. Sage Publications.

Azariadis, C., \& Allan, D. (1990). Threshold externalities in economic development. Quarterly Journal of Economics, (105), 501-526. http://dx.doi.org/10.2307/2937797

Barro, R. (1990). Government spending in a simple model of endogenous Growth. Journal of political economy. http://dx.doi.org/10.1086/261726

Barro, R. (1991). Economic growth in a cross section of countries. Quarterly Journal of Economics, 106(2), 407-443. http://dx.doi.org/10.2307/2937943

Checkel, J. T. (1998). The constructivist Turn in International Relations Theory. World politics, 2, 324-348. http://dx.doi.org/10.1017/S0043887100008133

Coyne, C. J., \& Williams, C. (2009). Trade Openness and Culture. Mimeo.

Cozzi, G. (1998). Culture as a bubble. Journal of Political Economy, (106), 376-394. http://dx.doi.org/10.1086/250013

Cypher, J. M., \& Dietz, J. L. (2004). The process of Economic Development (2nd ed., p. 229). London and New York: Rutledge.

Data, W. B. (2009). World Development Indicators. World Bank. Retrieved from http://www.data.worldbank.org

Denison, D. R., \& Mishra, A. (1996). Towards a theory of organizational culture and effectiveness. Organizational Science, 6(2), 204-223. http://dx.doi.org/10.1287/orsc.6.2.204

Fukuyama, F. (1995). Trust- The Social Virtues and the Creation of Prosperity. Free Press. New York.

Faria, R., Miguel A., \& Ledesma, L. (2004). Habit formation, work ethics and technological progress. University of Manchester, 72(3), 403-413. http://dx.doi.org/10.1111/j.1467-9957.2004.00399.x

Gunnar, M. (1957). Economic theory and underdeveloped regions. Hutchinson publications.

Granato, J., Inglehart, R., \& Leblang, D. (1996). The effect of cultural values on economic development: theory, hypotheses, and some empirical tests. American Journal of Political Science, 40(3), 607-631. http://dx.doi.org/10.2307/2111786

Hofstede, G. H. (1984). Culture consequences: International differences in work- related values. Beverly Hills: Sage.

House, R. J., Hanges, P. J., Javidan, M., Dorfman, P. W., \& Gupta, V. (2004). Culture, Leadership and Organizations: the GLOBE study of 62 societies. Sage Publication.

Jackman, R. W., \& Ross, A. M. (1996). The Poverty of Political Culture. American Journal of Political Science, 40(3), 697-716. http://dx.doi.org/10.2307/2111790

Johnson, J. P., \& Lenartowicz, T. (1998). Culture, freedom and economic growth: Do cultural values explain economic growth? Journal of World Business, 33(4), 332-356. 
Jonathan Hanson, K. (2009). Cultural values and economic growth: a new look at past findings. Syracuse University.

Herman, K. (1979). World Economic Development: 1979 and Beyond. West view Press.

Kroeber, A., \& Kluckhohn. (1952). Culture: A critical Review of concepts and Definitions. Cambridge, papers of Peabody museum of America Archeology and Ethnology, XLVII(1), 41-79.

Landes, D. (2000). Culture matters: how values shape human progress. (edited by L. E. Harrison, \& S. P. Huntington, 1st ed.). New York: Basic Books.

Lawrence, H. (1985). Underdevelopment is a state of mind (2nd ed.). New York: University Press of America.

Lawrence, H. (1997). The Pan American Dream-Do Latin America's cultural values discourage true partnership with the United States and Canada (1st ed., p. 33). New York: Basic Books.

Levine, R., \& Renelt, D. (1992). A sensitivity Analysis of cross- country growth Regressions. America economic review, 82(4), 942-963.

Lewis, A. (1955). The Theory of Economic Growth. London: Allen \& Unwin.

Lucas, R. (1988). The Mechanics of Economic Development. Journal of Monetary economics, (22), 3-42. http://dx.doi.org/10.1016/0304-3932(88)90168-7

Max, W. (1958). The Protestant Ethic and the Spirit of Capitalism. New York: Charles Scribner's Sons.

Mankiw, N. G., Romer, D., \& Weil, D. (1992). A Contribution to the Empirics of Economic Growth. Quarterly Journal of Economics, (152), 407-437. http://dx.doi.org/10.2307/2118477

McClelland, D. C. (1953). The Achievement motive. New York: Appleton-Century-Crosts. http://dx.doi.org/10.1037/11144-000

McClelland, D. C. (1961). The Achieving Society. Van Nostrand: Princeton.

McSweeney, B. (2002). Hofstede's Model of national cultural differences and their consequences: A triumph of faith- a failure of analysis. Human relations, 55(1), 89-118.

Muhammad, K., Jianhua, Z., Muhammad, S., \& Mohsin, B. (2010). Cultural values and economic Growth in Asia: An empirical analysis. International journal of Business and social sciences, 1(2). Retrieved from http://www.ijbssnet.com/journals/Vol._1_No._2_November_2010/3.pdf

Myrdal, G. (1968). Asian Drama: An inquiry into the poverty of Nations. The twentieth century fund.

North, D. (1990). Institutions, institutional change and economic performance. Cambridge: Cambridge university press. http://dx.doi.org/10.1017/CBO9780511808678

Orlando, P. (2006, March). A poverty of the mind. The New York Times, 13.

Petrakos, G., Paschalis, A., \& Pavleas, S. (2007). Determinant of Economic growth: the experts' view. Dynreg, 20. Retrieved from http://www.esri.ie/research/research_areas/international_economics/dynreg/papers/Working_Paper_No._ 20.pdf

Rittberger, V. (2002). Approaches to the Study of Foreign Policy Derived from International Relations Theory. A paper presented to ISA Annual meeting.

Sala-i-Martins, X. (1997). I just ran two million regressions. America Economic Review.

Schein, E. H. (1985). Organizational culture and leadership. Organizational culture and leadership (1st ed.). San Francisco: Jossey- Bass Publishers.

Schwartz, S. H. (1994). Beyond individualism/collectivism: new cultural dimensions of values. In U. Kim, H. C. Triandis, C. Kagitcibasi, S. C. Choi, \& G. Yoon (Eds.), Individualism and Collectivism: theory method and applications (pp. 85-119). Thousand Oaks, California: Sage Publication.

Shixue, J. (1998). Cultural factors and economic performance in East Asia and Latin America. Institute of Latin American Studies.

Solow, R. M. (1956). A contribution to the theory of economic growth. Quarterly Journal of Economics, (70), 65-94. http://dx.doi.org/10.2307/1884513

Survey, W. V. (2010). World Value Survey. Retrieved from http://www.worldvaluesurvey.org

Thomas, M. (1798). An essay on the principle of population. St. Paul's Church-Yard. Retrieved from http://www.esp.org/books/malthus/population/malthus.pdf

Tabellini, G. (2009). Culture and Institutions: Economic Development in the Regions of Europe. Journal of the European Economic Association.

Trompenaars, A., \& Hampden-Turner, C. (1997). Riding the waves of culture: understanding cultural diversity in global business (2nd ed.). New York: McGraw-Hill.

Vaughan, C. (2003). The organizational culture and effectiveness of companies involved in public sector housing construction in Hong Kong. CIB TG 23 International conferences. Hong Kong. 
Wilderom, C. P., Glunk, U., \& Maslowski, R. (2000). Culture as a predictor of organizational performance. In N. M. Ashkanasy, C. P. Wilderom, \& M. F. Peterson (Eds.), Handbook of organizational culture and climate (pp. 193-209). California: Sage Publications.

Yuriy, G., \& Roland, G. (2010). Culture, Institutions and the wealth of nations. Preliminary publication. Retrieved from http://emlab.berkeley.edu/ ygorodni/gorrol_culture.pdf

\section{Note}

Note 1 . The world value survey website is dedicated to issues relating to values and cultural changes. The survey circulates questionnaires across the globe in different societies and communities. The responses from these questionnaires are collected and defined as wave(s) representing a particular year(s). The survey began in 1981 and has since maintained its momentum having been able to reach more than 780 communities. It sometimes collaborates with the European value survey. The survey responses are published in SPSS and SAS formats and are available. See http://www.worldvaluessurvey.org

\section{Copyrights}

Copyright for this article is retained by the author(s), with first publication rights granted to the journal.

This is an open-access article distributed under the terms and conditions of the Creative Commons Attribution license (http://creativecommons.org/licenses/by/3.0/). 